\title{
Some Issues Facing Forest Resource Managers in Ontario
}

\author{
The following is from a submission to Ontario's Royal \\ Commission on the Northern Environment by the Faculty of \\ Forestry and Landscape Architecture, University of Toronto. \\ The submission "is intended to list some of the pertinent issues \\ facing forest resource managers in Ontario." We suggest that \\ many of the principles behind these issues should be of concern \\ to all forest resource managers. Your comments are invited.
}

\section{Support for the Royal Commission on the Northern Environment}

We support the Royal Commission on the Northern Environment. Our collective experience in teaching and research leads us to believe that there is a strong relationship between public understanding and political action. We have seen many examples of mismanagement of natural resources, such as conflicts in land use and forest management, brought about largely through public misunderstanding of the importance of maintaining the productive capacity of Ontario's lands and waters. An important outcome of the deliberations of the Royal Commission on the Northern Environment will be an improvement in public understanding which should lead ultimately to better management of our natural resources, not just for the northern environment but for all of Ontario. In fact, we suggest that the cost of the Royal Commission on the Northern Environment will be more than offset by gains in public understanding which will result in better resource management. Accordingly, we recommend that all public reports and documents arising from the Commission's activities be made easily accessible to students and teachers throughout Ontario.

\section{Constructive Review Needed to Update Natural Resource Legislation}

The disposition of timber rights in Ontario is administered under the authority of the Crown Timber Act. We believe the procedures used to award timber rights are unsatisfactory because they neither provide for the disposition of large tracts of timber on a competitive basis, as in the Reed situation, nor do they provide mechanisms for discussion by other people who may have interests or who may be significantly affected by implementation of the proposals. As a result, it is now imperative that the legislation under which our natural resources are dispensed, and the basic premises and attitudes on which this legislation is based, be carefully scrutinized. A critical review is particularly important for natural resources of a renewable nature, as are forests and wildlife populations, both of which can be profoundly affected by mismanagement of the forest lands which sustain them.

\section{Changing Responsibilities for Forest Management}

Discussions about the Reed proposal have served to emphasize a need to re-examine the basic premise of whether or not the government should be responsible for all management on all public lands. We are aware that, arising in part from the Armson report on "Forest Management in Ontario", discussions between the Ministry of Natural Resources and the forest industry are proceeding with a view to delegation by the Crown of forest management responsibilities for part of these public lands. This should not preclude an examination of what we believe is a most important and basic consideration by the Royal Commission; that is, the entire matter of management of renewable resources on Crown land and, if delegation of management is appropriate, whether or not other forms of land ownership or control should be considered.

\section{Support Needed Both for Planning and Implementation}

We have seen examples of good planning in Ontario discouraged by lack of political commitment to implement the plans. We suggest that it would be revealing for the Royal Commission to study the relationship between development of plans and commitment to their implementation. Two suggested areas include: (a) Forest production, which includes regeneration, where the policy proposed in 1972 was only $50 \%$ funded in 1977

(See Submission to the Royal Commission on Northern Environment by the Ministry of Natural Resources, November 1, 1977), and (b) The program to preserve and conserve Ontario's threatened and endangered species, which is supported by the Endangered Species Act, 1971, but which seems grossly underfunded.

\section{Intensive Forest Management in the North Needs Further Study}

Developments north of the $50^{\circ}$ latitude in Ontario must make provision for proper management of the forest resource. The Ministry of Natural Resources has indicated to the Royal Commission that intensive forest management is planned for this particular area 
(See Submission to the Royal Commission on Northern Environment by the Ministry of Natural Resources, November 1, 1977). Not all forest lands have the potential to be managed intensively. There are extensive areas of wetlands and of shallow soils over bedrock in the north. Experience south of the $50^{\circ}$ latitude indicates that these soil types are extremely sensitive and it is questionable, therefore, whether intensive forest management could be practiced on these lands.

Undoubtedly some soils within the region have the potential for intensive forest management but, before development occurs, there needs to be a delineation of lands capable of supporting intensive forestry and lands which would be extremely sensitive to disturbance. The primary problem is the scarcity of adequate information on the soils, climate and vegetation of this region and the potential for and effects of intensive forest management. Development of this forest resource must be undertaken in concert with an information gathering system which will allow for proper management decisions.

\section{Review Fire Management in the Boreal Forest}

Forest fire management in northern Ontario is the responsibility of the Ontario Ministry of Natural Resources. Approximately $30 \%$ of the land north of $50^{\circ}$ is managed to exclude wildfire. All wildfires that are detected are aggressively suppressed, if there are sufficient resources available. On the remaining $70 \%$ of the land only those fires that are thought to pose a threat to human safety or property are fought. History suggests that the Ministry of Natural Resources will expand the policy of wildfire exclusion north of $50^{\circ}$. We suggest the Royal Commission investigate the merits of wildfire exclusion. Although fires often pose a threat to human safety, property and valuable forest resources in populated areas, fire is a natural force that, under certain conditions, can benefit forest regeneration in the Boreal Forest. We see little need to spend large amounts of money to extinguish fires that may be beneficial to society.

\section{Enhance the Unique Landscape Elements of the North}

The qualitative aspects of both the natural and the cultural landscape "North of 50 " need careful assessment and incorporation into the planning process. The identification of historic and unique landscapes, both natural and man-made, is required to preserve landscape elements for future planning. Attention should be directed to the development of landscape design solutions to overcome existing and potential conflicts between resource extraction and human use. The use of vegetation for shelter in the north is particularly important, as well as developing forms of dwellings and architecture responsive to the northern climate and the northern people. Also important is landscape rehabilitation following extraction to encourage the re-establishment of desirable vegetation and wildlife, and to thereby permit continued human use of the land. The development of a comprehensive landscape management policy for Northern Ontario is needed to reflect present and future needs of its inhabitants, and of the people of Ontario as a whole.

\section{The Need for Natural Areas in the North}

We must harvest resources to live yet there is a compelling need to harvest wisely. A basic step in improving resource use is to compare harvested areas and products with those of a valid reference area. The reference area is kept as natural as possible and large enough to show the effect of natural processes There should be as many natural areas as there are broad types of forests in the north. Some areas should be the size of major watersheds. A comparison of the harvested and reference areas will show the effect of harvesting and provide a benchmark against which to measure improvements in methods of harvesting and production.

\section{Support for Local Participation in Resource Management}

The involvement of the regional inhabitants in the development and management of the natural resources of the north is essential. This will require inputs of capital and technology which generally are not available within the region itself. It should be kept in mind, however, that the resources being developed and managed are themselves a form of capital. Both regionally and provincially there must be a commitment by the Province for the reinvestment of some of this capital back into the management of these natural resources, and this reinvestment should largely involve local industry and people. Training and educational programs must be mounted where necessary to ensure the effectiveness of such reinvestment in the north.

\section{Priority Status to Maintaining Ontario's Biological Resource Base}

We suggest that the Royal Commission on the Northern Environment consider giving priority status to maintaining the biological resource base of the northern environment. Maintaining the ability of Ontario's biological resource base to contribute goods and services in perpetuity should be the highest priority in the Province. If the Royal Commission 
would accept this philosophy, then its mandate could become easier to fulfil. For example, we understand a major task of the Royal Commission on the Northern Environment is to evaluate the environmental impact of major new enterprises such as timber, minerals, oil and gas, pipelines, hydro-electric and nuclear power, tourism and recreation, and transportation and communications. We suggest instead the development and implementation of sound resource management policies and practices to ensure that the biological productivity of the northern environment is maintained, and that all enterprises be required to conform with the guidelines that will make this possible. Maintaining the biological resource base of the northern environment is essential to meet the long-term continuing needs of both the people of the north and of the south.

\section{Ontario Needs an Annual Focus on Its Changing Biological Resource Base}

In conclusion, we understand the Royal Commission plans to suggest ways to monitor the environmental effects of undertakings in the north. A new approach we suggest is to initiate the preparation and presentation of an annual biological report. This would include the appointment of a biological auditor responsible to present an annual report to parliament on the biological condition of Ontario's lands and waters. A parallel with the financial world is the auditor's report on the current financial situation. We maintain that parliament and the people need an annual focus on Ontario's changing biological resource base and propose the annual biological audit concept as a feasible way to monitor change.

\section{Predicting Growth of Canada's Forests: A Plan for Action}

To develop a rationale for a program of growth prediction that would provide reliable data for forest management planning, applicable at local, regional and national levels, it is worthwhile to review briefly the present knowledge regarding the significance of growth data in decision-making, and the technical requirements that have to be met in the collection and interpretation of such data.

Growth and decadence of trees and forests are two characteristics that set them apart from minerals and make possible their management as a renewable crop, capable of producing continuous yields of wood and its products under intelligent management. Growth, therefore, has been called the lifeblood of forest management and the essence of a continuing forest business. As a business enterprise, however, forestry has three characteristics that distinguish it from much of the remaining economy: the long period of production in timber growing; the fact that much timber is, at one and the same time, both capital plant and finished product; and the fact that many forest values are not directly measured by existing markets.

To be able to make decisions about the most desirable level of forest management as a basis of a continuing forest business, important questions must first be asked, such as: - Is more land needed to support the forestry sector of the economy, or can enough wood be grown with more intensive management of presently existing forest lands? Can production be increased on the basis of increased yields anticipated, or must it be reduced because available raw material cannot support it on a continuing basis? To answer these questions, information is needed on the per hectare growth, the cost of growing wood, and the value of the wood produced.

Information on the per hectare growth by species, stand density, site quality and stand age defines the limits of the amount of wood that a given piece of land is capable of producing. When growth information is combined with information on the intended level of forest management and the costs of it, such as the price of land the associated carrying charges, the cost of planting stock and that of planting, the cost of stand treatments and that of protection, and the cost of harvesting, the cost of wood that a given piece of land can produce can be calculated.

When cost information is combined with information on the physical and chemical properties of the wood associated with a given level of forest management, from which the value of the wood produced can be derived, the amount of wood that a given piece of land is capable of producing can be translated into value units.

The technical requirements that have to be met in the collection and interpretation of the per hectare growth data derive basically from two considerations. First, growth problems relate to prediction, not to past growth determination. Information is necessarily obtained from past growth 